\title{
Compact Double-P Slotted Inset-Fed Microstrip Patch Antenna on High Dielectric Substrate
}

\author{
M. R. Ahsan, ${ }^{1}$ M. T. Islam, ${ }^{1}$ M. Habib Ullah, ${ }^{1,2}$ W. N. L. Mahadi, ${ }^{2}$ and T. A. Latef ${ }^{2}$ \\ ${ }^{1}$ Department of Electrical, Electronic and Systems Engineering, Faculty of Engineering and Built Environment, \\ Universiti Kebangsaan Malaysia (UKM), 43600 Bangi, Selangor, Malaysia \\ ${ }^{2}$ Department of Electrical Engineering, Faculty of Engineering, University of Malaya (UM), 50603 Kuala Lumpur, Malaysia
}

Correspondence should be addressed to W. N. L. Mahadi; wnliza@um.edu.my

Received 25 April 2014; Revised 13 July 2014; Accepted 14 July 2014; Published 5 August 2014

Academic Editor: Jaume Anguera

Copyright (C) 2014 M. R. Ahsan et al. This is an open access article distributed under the Creative Commons Attribution License, which permits unrestricted use, distribution, and reproduction in any medium, provided the original work is properly cited.

\begin{abstract}
This paper presents a compact sized inset-fed rectangular microstrip patch antenna embedded with double-P slots. The proposed antenna has been designed and fabricated on ceramic-PTFE composite material substrate of high dielectric constant value. The measurement results from the fabricated prototype of the antenna show $-10 \mathrm{~dB}$ reflection coefficient bandwidths of $200 \mathrm{MHz}$ and $300 \mathrm{MHz}$ with center resonant frequency of $1.5 \mathrm{GHz}$ and $4 \mathrm{GHz}$, respectively. The fabricated antenna has attained gains of $3.52 \mathrm{dBi}$ with $81 \%$ radiation efficiency and $5.72 \mathrm{dBi}$ with $87 \%$ radiation efficiency for lower band and upper band, respectively. The measured E- and $\mathrm{H}$-plane radiation patterns are also presented for better understanding. Good agreement between the simulation and measurement results and consistent radiation patterns make the proposed antenna suitable for GPS and C-band applications.
\end{abstract}

\section{Introduction}

In the past couple of years, the emerging trends of wireless and mobile communications technology always requested optimum utilization of the productive resources by ensuring multiple quality services with a single device component. The expected scenario is certainly directed towards the size reduction of the multiple frequency band antennas of low profile, enhanced portability, and multifunctionality [1-4]. Nevertheless, with the increase of frequency bands, the design complexity associated with antenna also intensified. To fulfill the great demand of multifrequency operations in a single component for various wireless communication services, high performance antennas with desired radiation properties have to be developed. For the designing of communication module, it is common to integrate own antenna subsystem which can reciprocate certain standard requirements by wireless system. However, implementing and/or integrating more than one function in the single communication system may help in cost minimization and size reduction of the complete module. For outdoor environment, the position data of an object are given by the global positioning system (GPS) based on the satellite navigation system [5]. Integrating the GPS and C-band satellite frequency in a single antenna module may help in developing centralized remote monitoring system and thus may improve the robustness and efficiency in tracking/monitoring the position of flying aircrafts.

The microstrip patch antennas provide the conveniences through low cost, ease of manufacturability, easy integration, and adaptability with integrated circuit technologies. However, its main weakness is linked with narrow band service [6-8]. This can be overcome by implementing various band widening and size reduction techniques as reported by many researchers. Besides the wide bandwidth and low profile, the antenna has to be cost effective, offer steady radiation patterns, and provide consistent gain for multiband operations. Extensive research works have been carried out in the past years regarding the applications and technologies accompanying the multiband antenna design. By studying ample numbers of research articles, wide variations have been observed as expected in terms of geometrical configurations, size, substrate materials, manufacturing techniques, and analysis methods. A wide range of methods are reported in literatures for achieving reduced antenna size and obtaining 
more than one frequency band of operations. Some of the techniques involve using rectangular slotted patch [9], circular ring [10], defected ground plane $[11,12]$, metamaterials [13, 14], electromagnetic band-gap [15], high dielectric substrate $[16,17]$, magnetodielectric material [18], fractal shape $[19,20]$, split ring [21, 22], various feeding techniques [23-25], stacked arrangement $[26,27]$, and optimization technique like genetic algorithms [28, 29]. None the less, still there is room for further development of techniques to enhance the design simplicity, flexibility of operations, and tunable functionality of multifrequency besides maintaining the desired antenna properties for the implementation of the compact wireless device.

This paper proposes a $30 \times 35 \times 1.905 \mathrm{~mm}^{3}(W \times L \times h)$ rectangular patch antenna loaded with double-P slots and fed by a $7.5 \mathrm{~mm}$ long inset microstrip line. On the basis of the well-established mathematical formulation [30], the initial dimension of the microstrip patch antenna has been estimated for desired frequencies. The optimal dimension of the proposed antenna has been achieved through various simulations in finite element method based 3D full-wave electromagnetic high frequency structure simulator (HFSS) [31]. The antenna is designed and fabricated on ceramicpolytetrafluoroethylene (PTFE) composite material substrate with $\varepsilon_{r}=10.2, \tan (\delta)=0.0023$. The usage of high dielectric substrate though reduces the operating bandwidth; however, it assists to achieve the required miniaturization profile of the antenna [32, 33]. The fabricated prototype of the proposed antenna has achieved the resonant frequencies at $1.5 \mathrm{GHz}$ and $4.0 \mathrm{GHz}$ with $200 \mathrm{MHz}$ and $300 \mathrm{MHz}$ bandwidth, respectively. The operating bands of the antenna can successfully cover the $L_{1}$ GPS (1572 MHz) operating frequencies [34] and C-band applications [21]. The proposed antenna has obtained a peak gain of $3.52 \mathrm{dBi}$ with $81 \%$ efficiency and $5.72 \mathrm{dBi}$ with $87 \%$ efficiency for lower band and upper band, respectively. The experimental verification has concluded with good agreement between the measured results from fabricated antenna and the simulation results.

\section{Antenna Design}

Figure 1 represents the fabricated antenna prototype alongside the schematic of the double-P shape slotted inset-fed patch antenna structure. The complete optimized parameters for the proposed antenna are offered in Table 1. Alike typical microstrip antenna, the proposed antenna is made up of a mirrored P-shape slotted radiating patch, a $50 \Omega$ microstrip line inset-fed mechanism, and simple rectangular partial ground plane on the rear side of the substrate. Since the length of the ground plane has a dominant effect on resonant frequency and impedance bandwidth [35], the partial/defected ground plane is chosen by researchers for reduced reflection coefficient and wider gain $[36,37]$. The proposed microstrip line inset-fed double-P slotted planar antenna is designed and numerically analyzed by employing HFSS 3D electromagnetic simulator, which is based on the frequency domain solver. The final optimized design of the antenna is printed on a $1.905 \mathrm{~mm}$ thick ceramic-PTFE composite material substrate with $\varepsilon_{r}=10.2, \tan (\delta)=0.0023$, and dimensions of $30 \times 35 \mathrm{~mm}^{2}(W \times L)$ by means of inhouse printed circuit board (PCB) prototyping machine. The geometrical configuration of the radiating patch element is estimated and optimal parameters are being searched through the use of electromagnetic simulator. To cope up with the expected multifrequency operations, the augmented measurements for the ground plane and dielectric substrate are chosen wisely. A microstrip line of $7.5 \mathrm{~mm}$ long and $1.5 \mathrm{~mm}$ wide inset-feeding mechanism is selected to connect the radiating patch along with the partial ground plane of $5 \times$ $30 \mathrm{~mm}^{2}$ through a $50 \Omega$ coaxial probe at the center of $x$-axis and along the $y$-axis. The microstrip line is copper imprinted alongside with the patch on the substrate as the radiator. The details of the proposed antenna parameters are tabulated in Table 1.

\section{Experimental Verifications}

The experimental prototype of the proposed antenna has been fabricated using printed circuit board for verifying and comparing its performance results with the expected one from numerical simulation. Consequently, the PCB model of the antenna is tested in a typical anechoic antenna measurement chamber system with a horn antenna as a reference [38]. Figure 1(b) shows the picture of the PCB model of the proposed antenna for dual band operations. Simulated and measured reflection coefficient versus frequency is shown in Figure 2. The measured reflection coefficient exhibits the operating bands, from $1.35 \mathrm{GHz}$ to $1.55 \mathrm{GHz}$ and from $3.9 \mathrm{GHz}$ to $4.2 \mathrm{GHz}$ at lower and upper bands, consecutively. There is a little dissimilarity between simulated and measured reflection coefficient observed and it can be due to the fringing effect caused by the SMA soldering imperfection. The achieved gain and radiation efficiency of the antenna are demonstrated in Figure 3. It has been realized that average gain is $3.49 \mathrm{dBi}$ with $80 \%(0.80)$ radiation efficiency in the lower band and $5.40 \mathrm{dBi}$ with $85 \%$ (0.85) in the upper band, correspondingly. At the lower and upper resonant frequencies $3.52 \mathrm{dBi}$ and $5.72 \mathrm{dBi}$ gains and $81 \%$ and $87 \%$ radiation efficiencies have been achieved, respectively. As the gain of the radiating structure is proportional to the concentration of the surface current, it can be further validated by the electric field distribution illustrated in Figure 4. It can be evidently perceived that the intensity of the flowing current is comparatively lower than upper band. Similarly, as observed in gain profile, the radiation is much stronger in the upper band compared to the lower band.

From the surface current distribution outline, the resonant characteristics can also be realized. The lower resonant frequency is obtained through the slots on the lower edge of the radiating patch; particularly " $\mathrm{P}$ " shaped slot closed to the microstrip feed line, whereas upper edge of the radiating patch radiates minimum at the lower resonance. Furthermore, the upper edge, especially around the cutting edge of inverse " $\mathrm{P}$ " slot, is responsible for the higher resonant frequency. The measured radiation pattern of the proposed antenna is demonstrated in Figure 5. Symmetric and nearly 
TABLE 1: Optimal dimensions of the proposed antenna.

\begin{tabular}{lcccccccccccccccccccccc}
\hline Parameters & $W$ & $W_{1}$ & $W_{2}$ & $W_{3}$ & $W_{4}$ & $W_{5}$ & $W_{6}$ & $W_{s}$ & $W_{i}$ & $W_{f}$ & $W_{d}$ & $L$ & $L_{p}$ & $L_{1}$ & $L_{2}$ & $L_{3}$ & $L_{4}$ & $L_{5}$ & $L_{6}$ & $L_{s}$ & $L_{g}$ & $L_{f}$ \\
\hline Dimension $(\mathrm{mm})$ & 30 & 5 & 3.5 & 4.5 & 4.5 & 4.5 & 5 & 1.5 & 0.25 & 1.5 & 14 & 35 & 30 & 7 & 4.25 & 3 & 4.25 & 7 & 5 & 1 & 0.25 & 9.5
\end{tabular}

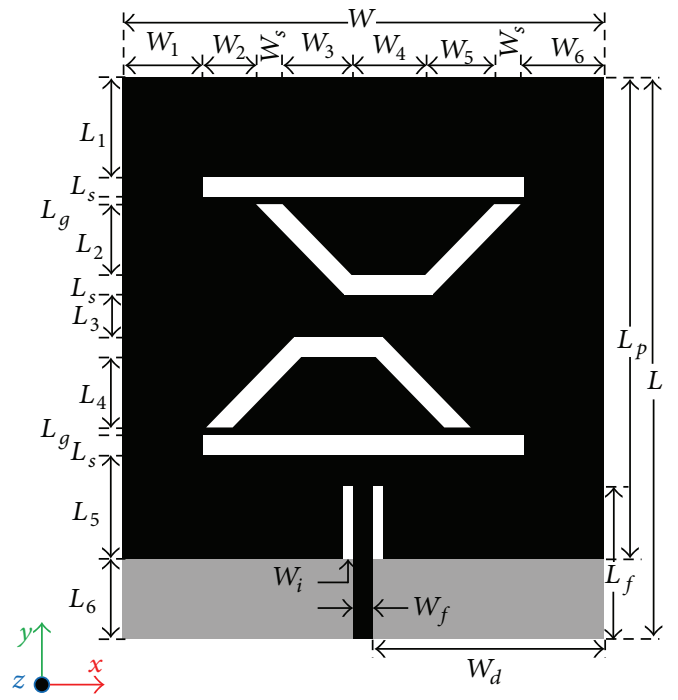

(a) Geometry

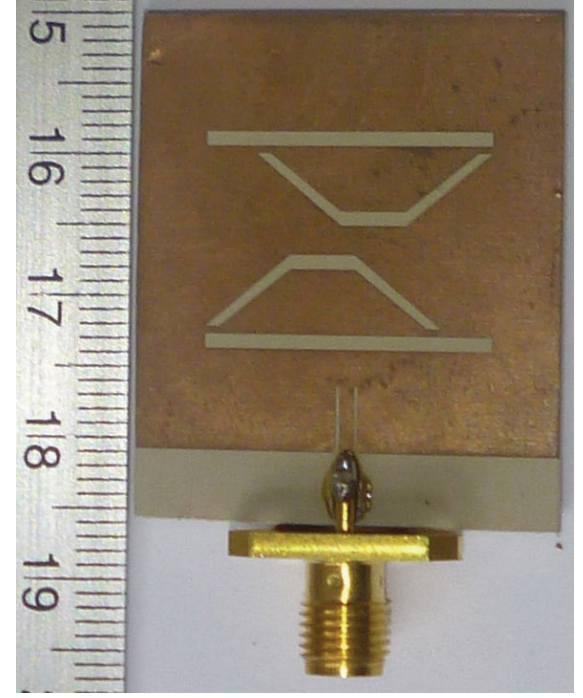

(b) Prototype

FIGURE 1: Layout of the proposed antenna (a) geometrical configuration and (b) printed prototype.

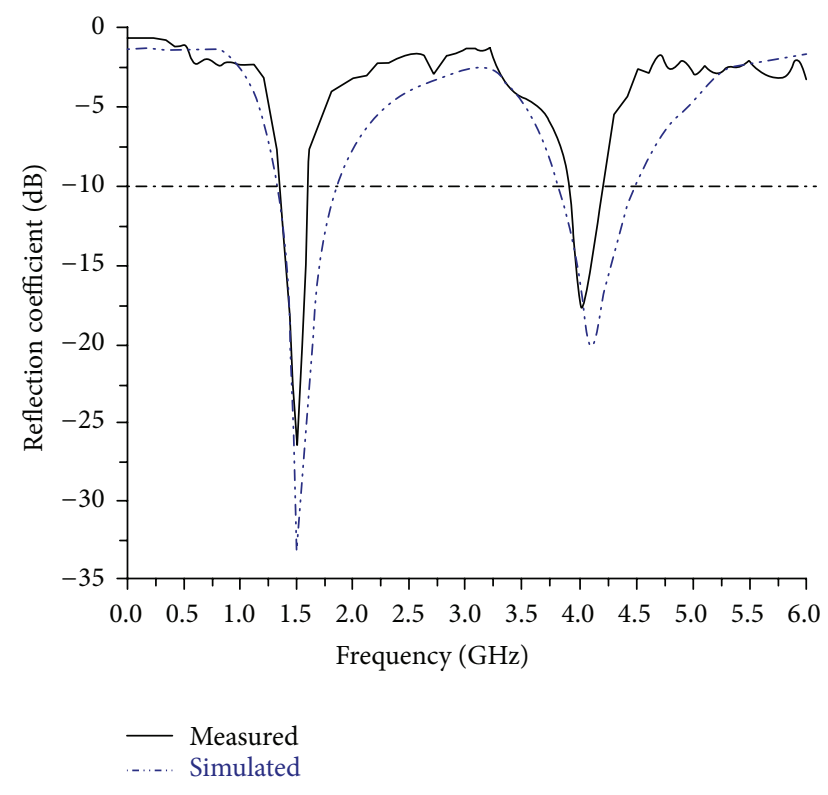

Figure 2: Predicted and experimented reflection coefficient of the proposed antenna prototype.

stable radiation profiles at both lower and upper resonance have been realized. The cross polar effects at both resonant frequencies are comparatively lower. A Co-polar $-3 \mathrm{~dB}$ half power beam width (HPBW) of $109^{\circ}\left(54^{\circ}-0^{\circ}-304^{\circ}\right)$ in Eplane and $95^{\circ}\left(54^{\circ}-0^{\circ}-318^{\circ}\right)$ at $1.5 \mathrm{GHz}$ has been measured at broadside direction. Furthermore, at the higher resonance of

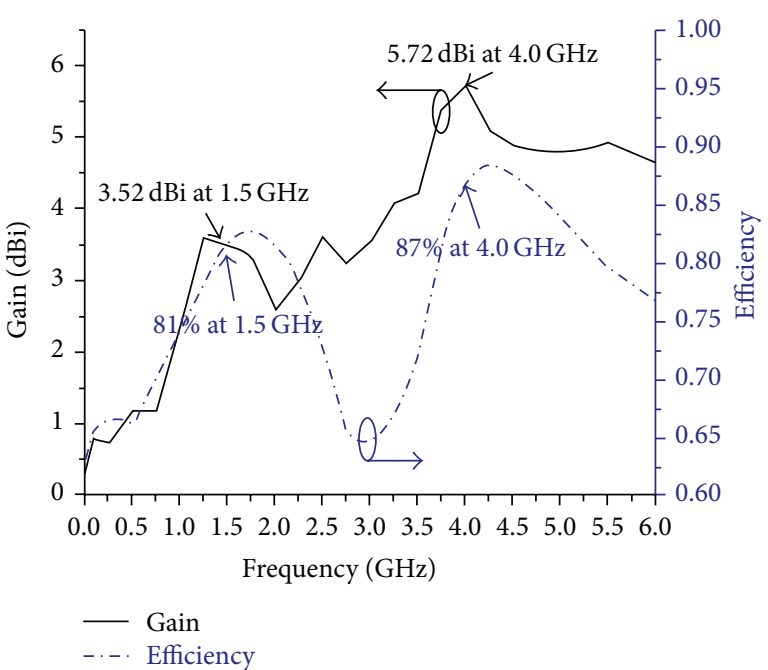

FIGURE 3: Achieved gain and radiation efficiency of the proposed antenna.

4.0 GHz HPBW of $71^{\circ}\left(48^{\circ}-0^{\circ}-336^{\circ}\right)$ in E-plane and $65^{\circ}\left(26^{\circ}-\right.$ $\left.0^{\circ}-330^{\circ}\right)$ in $\mathrm{H}$-plane has been observed. However, a little back lobe radiation has been noticed at $4.0 \mathrm{GHz}$. A considerable amount of back lobe radiation is being observed and possible reason behind this may be the utilization of small sized partial ground plane. Full ground plane may reduce the back lobe; conversely, this may affect the resonant frequencies, gain, and bandwidth of the proposed antenna which is undesirable. Furthermore, this study has been done for achieving certain 


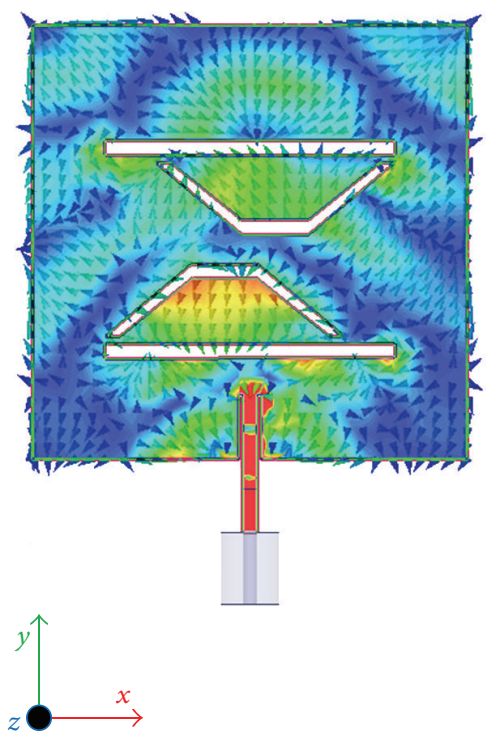

(a)

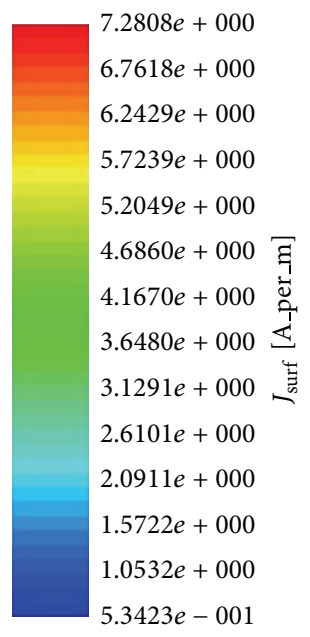

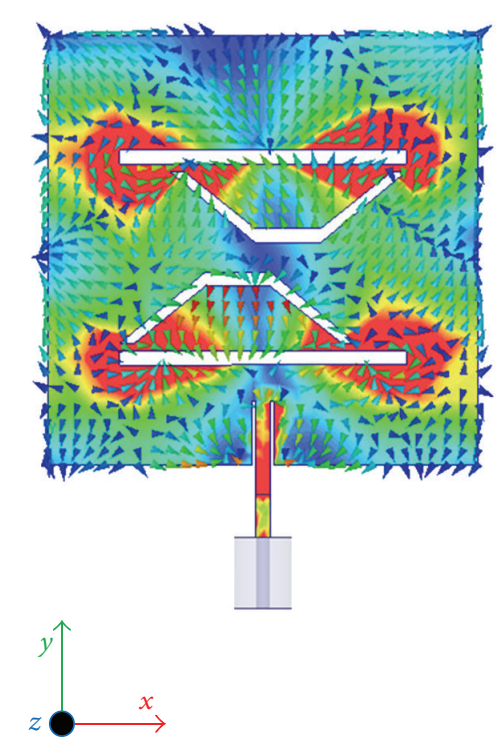

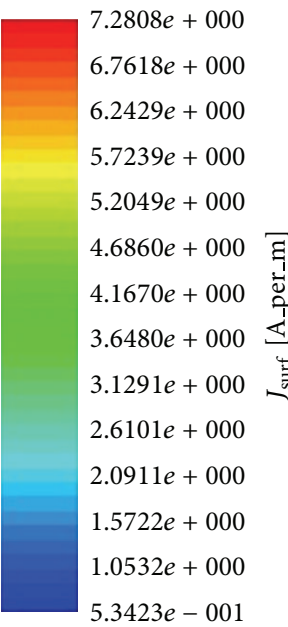

(b)

FIGURE 4: Surface current distribution at (a) lower and (b) upper resonant frequencies of the proposed antenna.

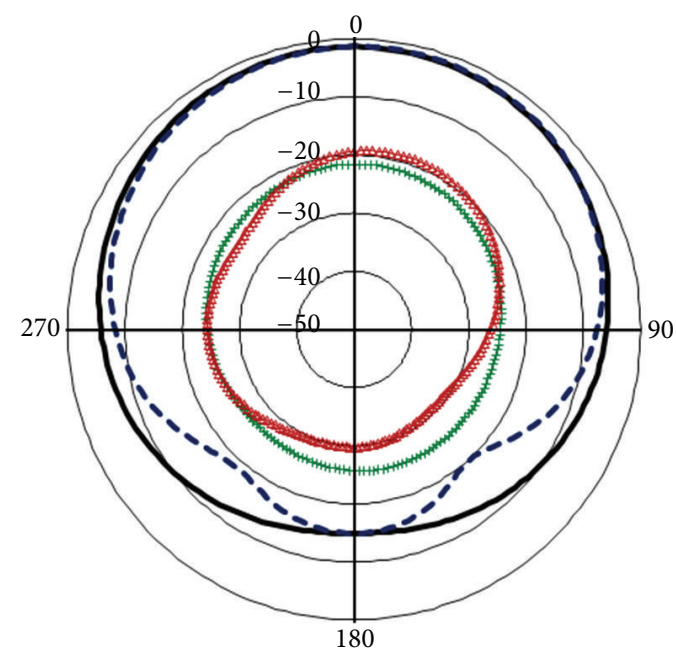

- E-plane Co-polar

+ E-plane cross polar

$\triangle$ H-plane cross polar

(a) $1.5 \mathrm{GHz}$
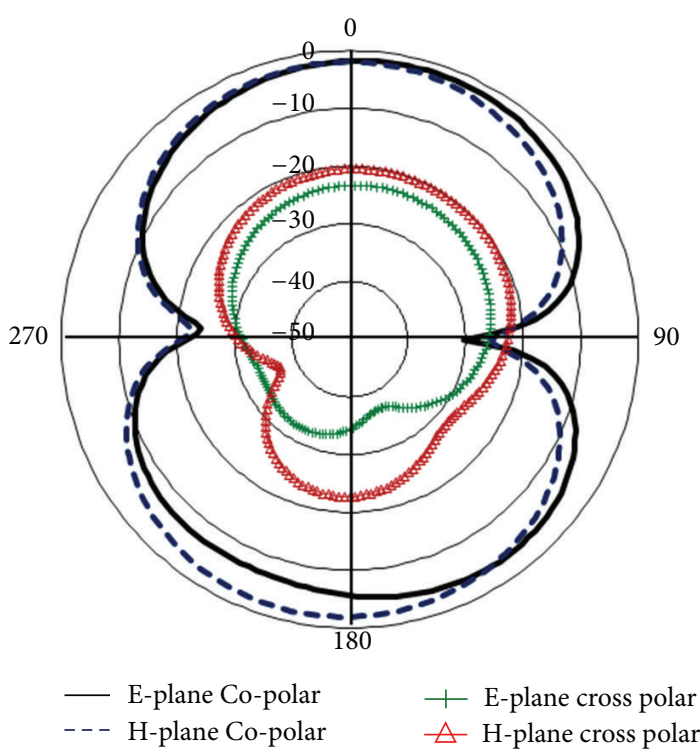

(b) $4 \mathrm{GHz}$

FIGURE 5: Measured radiation profile of the fabricated antenna.

resonant frequencies; however, still there are possibilities in finding the proper solution for reduced back lobe. Input impedance and VSWR of the proposed antenna can be realized from the smith chart as shown in Figure 6. Both operating bands lie inside the VSWR 2:1 circle; the input impedance is close to $50 \Omega$. The lower resonant frequency lies below the zero line which is capacitive and the upper resonant frequency lies above the zero line, that is, inductive.

\section{Conclusion}

This paper demonstrates the development of inset-fed rectangular microstrip patch antenna with double-P slots. The printed planar antenna has gained the operating frequencies of $1.5 \mathrm{GHz}$ and $4 \mathrm{GHz}$, which can be utilized for GPS operating frequency and C-band applications. The proposed antenna has achieved bandwidths of $200 \mathrm{MHz}$ and $300 \mathrm{MHz}$ 


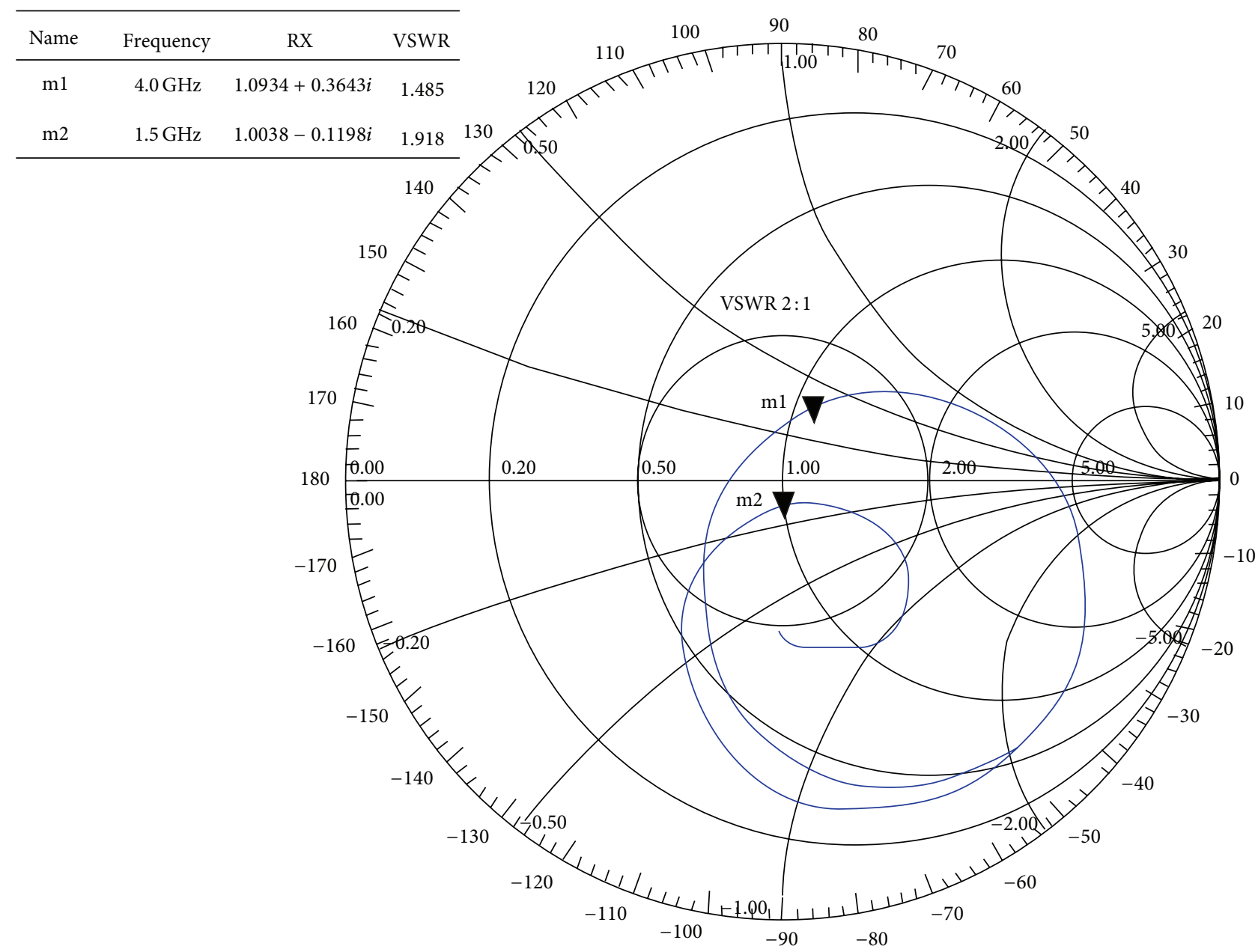

FIGURE 6: Smith chart of the proposed antenna.

with gain of $3.52 \mathrm{dBi}$ and $5.72 \mathrm{dBi}$, and radiation efficiency of $81 \%$ and $87 \%$ for lower band and upper band, respectively. The experimental results for fabricated antenna show good agreement with the simulation results obtained from commercially available finite element based simulator HFSS.

\section{Conflict of Interests}

The authors declare that there is no conflict of interests regarding the publication of this paper.

\section{Acknowledgment}

The authors would like to express their thanks to the Center of Research Grant Management (PPGP), University of Malaya, with Grant Postgraduate Research Fund (PPP) PG092-2012B for funding this project.

\section{References}

[1] J. Anguera, C. Puente, and C. Borja, "A procedure to design stacked microstrip patch antennas based on a simple network model," Microwave and Optical Technology Letters, vol. 30, no. 3, pp. 149-151, 2001.

[2] M. R. Ahsan, M. T. Islam, and M. H. Ullah, "A compact multiband inverted a-shaped patch antenna for WiMAX and Cband," Microwave and Optical Technology Letters, vol. 56, no. 7, pp. 1540-1543, 2014.

[3] D. M. Pozar, "Microstrip antennas," Proceedings of the IEEE, vol. 80, no. 1, pp. 79-91, 1992.

[4] M. John and M. J. Ammann, "Integrated antenna for multiband multi-national wireless combined with GSM1800/ PCS1900/IMT2000 + extension," Microwave and Optical Technology Letters, vol. 48, no. 3, pp. 613-615, 2006.

[5] S. Chen, G. Liu, X. Chen, T. Lin, X. Liu, and Z. Duan, "Compact dual-band GPS microstrip antenna using multilayer LTCC substrate," IEEE Antennas and Wireless Propagation Letters, vol. 9, pp. 421-423, 2010.

[6] M. Ojaroudi, N. Ojaroudi, and N. Ghadimi, "Enhanced bandwidth small square slot antenna with circular polarization characteristics for WLAN/WiMAX and C-band applications," Applied Computational Electromagnetics Society Journal, vol. 28, no. 2, pp. 156-161, 2013.

[7] M. R. Ahsan, M. T. Islam, M. H. Ullah, and N. Misran, "Bandwidth enhancement of a dual band planar monopole 
antenna using meandered microstrip feeding," The Scientific World Journal, vol. 2014, Article ID 856504, 8 pages, 2014.

[8] J. Anguerat, J. P. Daniel, C. Borja et al., "Metallized foams for antenna design: application to fractal-shaped sierpinski-carpet monopole," Progress in Electromagnetics Research, vol. 104, pp. 239-251, 2010.

[9] A. Buerkle, K. Sarabandi, and H. Mosallaei, "Compact slot and dielectric resonator antenna with dual-resonance, broadband characteristics," IEEE Transactions on Antennas and Propagation, vol. 53, no. 3, pp. 1020-1027, 2005.

[10] S. K. Gupta, M. Sharma, B. K. Kanaujia, A. Gupta, and G. P. Pandey, "Triple band annular ring loaded stacked circular patch microstrip antenna," Wireless Personal Communications, vol. 77, no. 1, pp. 633-647, 2014.

[11] S. A. Hosseini, Z. Atlasbaf, and K. Forooraghi, "Two new loaded compact planar ultra-wideband antennas using defected ground structures," Progress in Electromagnetics Research B, vol. 2, pp. 165-176, 2008.

[12] A. Andújar and J. Anguera, "Multiband coplanar ground plane booster antenna technology," Electronics Letters, vol. 48, no. 21, pp. 1326-1328, 2012.

[13] D. K. Ntaikos, N. K. Bourgis, and T. V. Yioultsis, "Metamaterialbased electrically small multiband planar monopole antennas," IEEE Antennas and Wireless Propagation Letters, vol. 10, pp. 963-966, 2011.

[14] Y. Li and Q. Feng, "A compact tri-band monopole antenna with metamaterial loaded for WLAN/WiMAX applications," Journal of Electromagnetic Waves and Applications, vol. 27, no. 6, pp. 772-782, 2013.

[15] J.-J. Xie, Y.-Z. Yin, J. Wang, and S.-L. Pan, "A novel triband circular slot patch antenna with an EBG structure for WLAN/WiMAX applications," Journal of Electromagnetic Waves and Applications, vol. 26, no. 4, pp. 493-502, 2012.

[16] R. G. Madhuri, P. M. Hadalgi, and P. V. Hunagund, "Design of high-permittivity rectangular dielectric resonator antenna," Microwave and Optical Technology Letters, vol. 53, no. 5, pp. 1077-1079, 2011.

[17] M. H. Ullah and M. T. Islam, "A compact square loop patch antenna on high dielectric ceramic-PTFE composite material," Applied Physics A: Materials Science \& Processing, pp. 1-9, 2013.

[18] A. Buerkle and K. Sarabandi, "A circularly polarized magnetodielectric resonator antenna with wideband, multi-resonant response," in Proceedings of the IEEE Antennas and Propagation Society International Symposium, vol. 1, pp. 487-490, Washington, DC, USA, July 2005.

[19] N. Saluja and R. Khanna, "A novel method to improve current density in multiband triangular fractal antenna," Electronics and Electrical Engineering, vol. 18, no. 10, pp. 41-44, 2012.

[20] J. Anguera, C. Puente, C. Borja, and J. Soler, "Dual-frequency broadband-stacked microstrip antenna using a reactive loading and a fractal-shaped radiating edge," IEEE Antennas and Wireless Propagation Letters, vol. 6, pp. 309-312, 2007.

[21] S. H. Yusop, N. Misran, M. T. Islam, and M. Y. Ismail, "Design of high performance dual frequency concentric split ring square element for broadband reflectarray antenna," Applied Computational Electromagnetics Society Journal, vol. 27, no. 4, pp. 334-339, 2012.

[22] D. Li, Y. J. Xie, P. Wang, and R. Yang, "Applications of split-ring resonances on multi-band frequency selective surfaces," Journal of Electromagnetic Waves and Applications, vol. 21, no. 11, pp. 1551-1563, 2007.
[23] M. T. Islam, M. N. Shakib, and N. Misran, "Design analysis of high gain wideband L-probe fed microstrip patch antenna," Progress in Electromagnetics Research, vol. 95, pp. 397-407, 2009.

[24] Z. Wang, S. Fang, S. Fu, and S. Jia, "Single-fed broadband circularly polarized stacked patch antenna with horizontally meandered strip for universal UHF RFID applications," IEEE Transactions on Microwave Theory and Techniques, vol. 59, no. 4, pp. 1066-1073, 2011.

[25] Y. Zhou, C.-C. Chen, and J. L. Volakis, "Dual band proximityfed stacked patch antenna for tri-band GPS applications," IEEE Transactions on Antennas and Propagation, vol. 55, no. 1, pp. 220-223, 2007.

[26] J. Anguera, C. Puente, C. Borja, N. Delbene, and J. Soler, "Dualfrequency broad-band stacked microstrip patch antenna," IEEE Antennas and Wireless Propagation Letters, vol. 2, pp. 36-39, 2003.

[27] M. H. Ullah, M. T. Islam, M. S. Jit, and N. Misran, "A threestacked patch antenna using high-dielectric ceramic material substrate," Journal of Intelligent Material Systems and Structures, vol. 23, no. 16, pp. 1827-1832, 2012.

[28] Y. Rahmat-Samii and E. Michielssen, Electromagnetic Optimization by Genetic Algorithms, John Wiley \& Sons, 1999.

[29] J. Jayasinghe, J. Anguera, and D. Uduwawala, "Genetic algorithm optimization of a high-directivity microstrip patch antenna having a rectangular profile," Radioengineering, vol. 22, no. 3, pp. 700-707, 2013.

[30] C. A. Balanis, Antenna Theory: Analysis and Design, John Wiley \& Sons, Hoboken, NJ, USA, 3rd edition, 2005.

[31] ANSYS, High Frequency Structural Simulator (HFSS), ANSYS.

[32] K.-L. Wong, Compact and Broadband Microstrip Antennas, Wiley, Hoboken, NJ, USA, 2004.

[33] Z. Peng, H. Wang, and X. Yao, "Dielectric resonator antennas using high permittivity ceramics," Ceramics International, vol. 30, no. 7, pp. 1211-1214, 2004.

[34] S.-L. Ma and J.-S. Row, "Design of single-feed dual-frequency patch antenna for GPS and WLAN applications," IEEE Transactions on Antennas and Propagation, vol. 59, no. 9, pp. 3433-3436, 2011.

[35] M. T. Nguyen, B. Kim, H. Choo, and I. Park, "Effects of ground plane size on a square microstrip patch antenna designed on a low-permittivity substrate with an air gap," in Proceedings of the International Workshop on Antenna Technology (iWAT '10), pp. 1-4, Lisbon, Portugal, March 2010.

[36] L. H. Weng, Y.-C. Guo, X.-W. Shi, and X.-Q. Chen, "An overview on defected ground structure," Progress in Electromagnetics Research B, vol. 7, pp. 173-189, 2008.

[37] R. Azim, M. T. Islam, and N. Misran, "Ground modified doublesided printed compact UWB antenna," Electronics Letters, vol. 47, no. 1, pp. 9-11, 2011.

[38] L. V. Blake and M. W. Long, Antennas: Fundamentals, Design, Measurement, SciTech Publishing, Raleigh, NC, USA, 2009. 

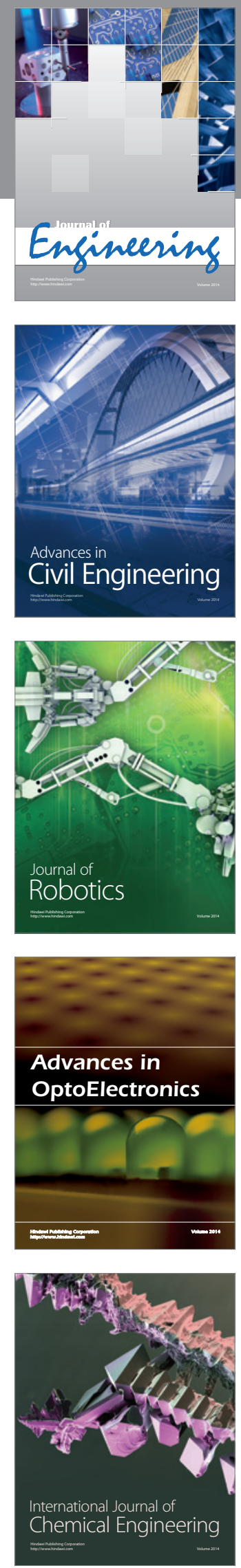

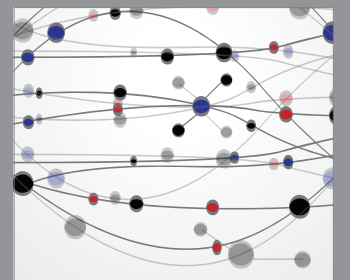

The Scientific World Journal
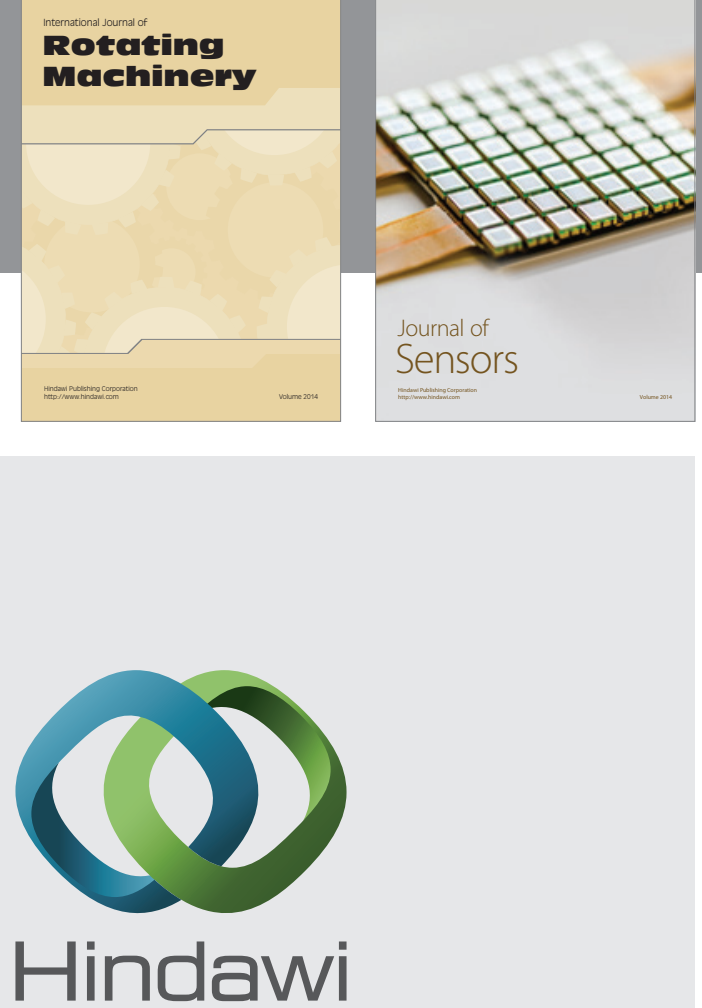

Submit your manuscripts at http://www.hindawi.com
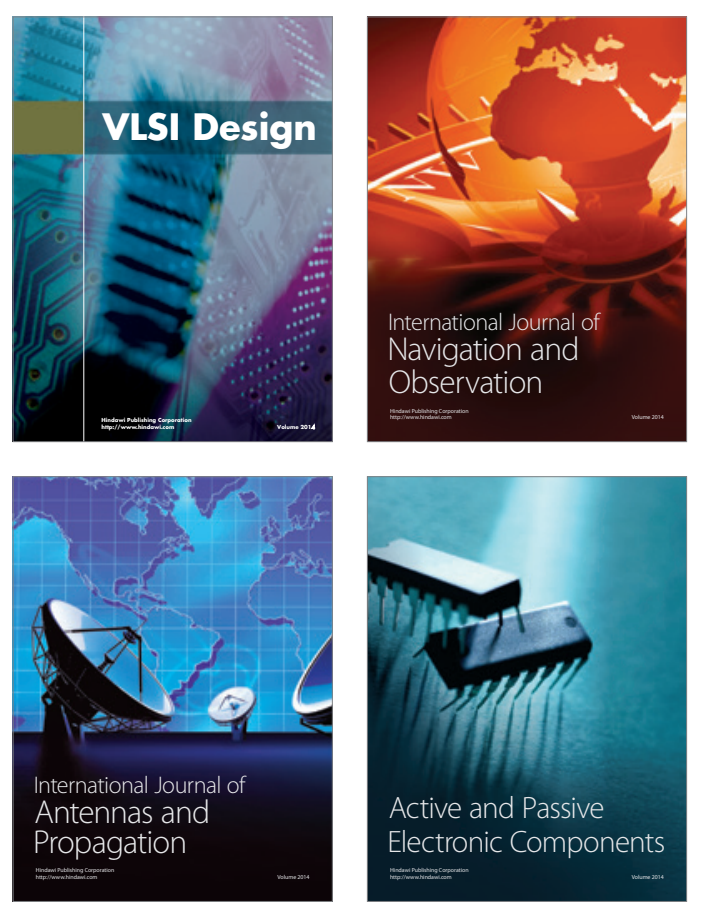
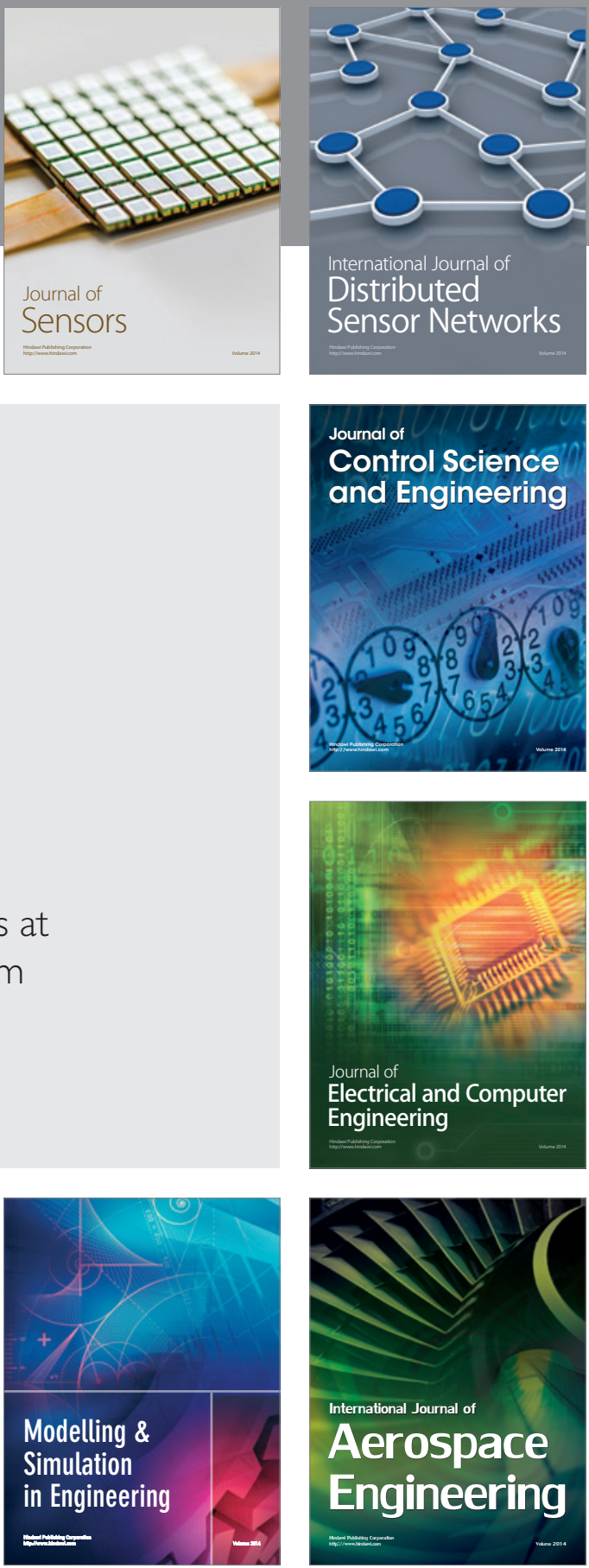

Journal of

Control Science

and Engineering
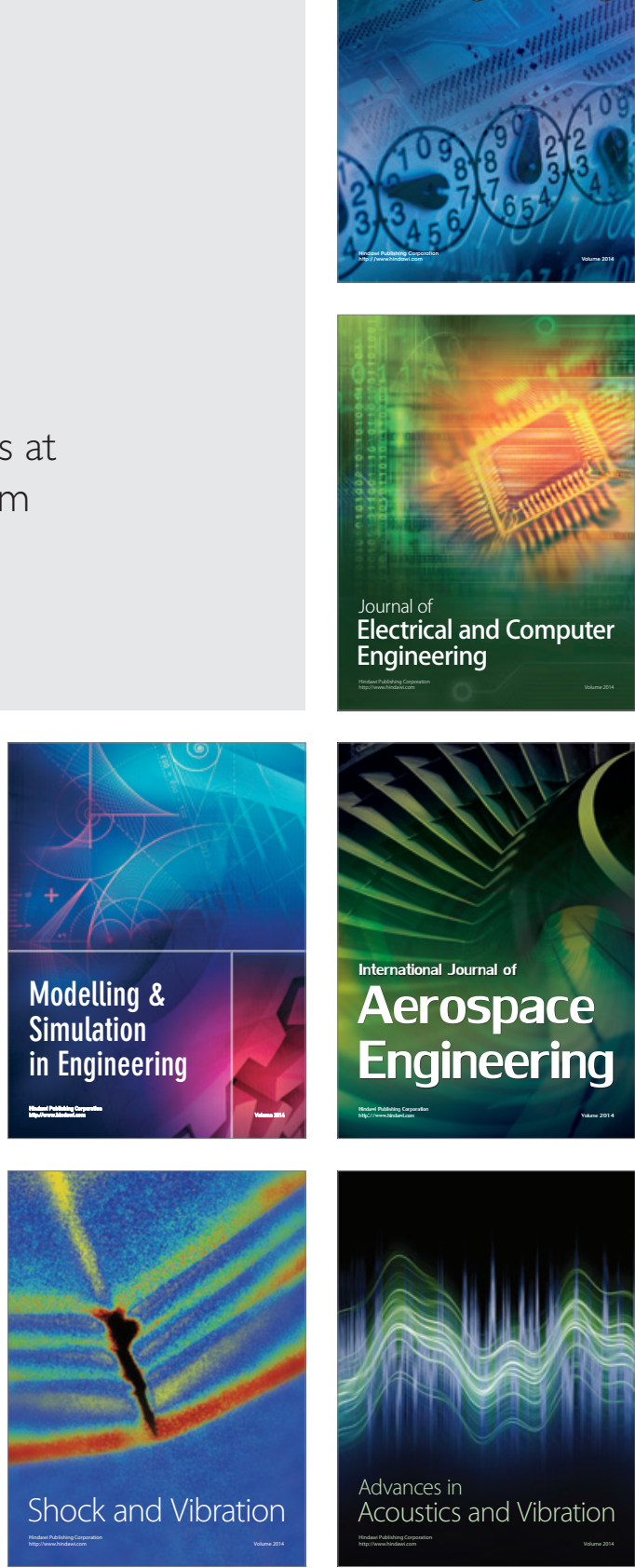